\title{
Impacts of Cloud Cover and Dust on the Performance of Photovoltaic Module in Niamey
}

\author{
Abdoulatif Bonkaney, ${ }^{1}$ Saïdou Madougou, ${ }^{1,2}$ and Rabani Adamou ${ }^{1,2}$ \\ ${ }^{1}$ WASCAL MRP Climate Change and Energy, University Abdou Moumouni, Niamey, Niger \\ ${ }^{2}$ University Abdou Moumouni, Niamey, Niger \\ Correspondence should be addressed to Abdoulatif Bonkaney; babdoulatif@yahoo.fr
}

Received 20 May 2017; Accepted 16 July 2017; Published 7 September 2017

Academic Editor: Xinhai Xu

Copyright (c) 2017 Abdoulatif Bonkaney et al. This is an open access article distributed under the Creative Commons Attribution License, which permits unrestricted use, distribution, and reproduction in any medium, provided the original work is properly cited.

The sensitivity of monocrystalline solar module towards dust accumulation and cloud cover is investigated from May to August 2015 for Niamey's environment. Two solar modules with the same characteristics have been used to assess the impacts of the dust on the solar PV module. One of the modules is being cleaned every morning and the second one was used for monitoring the effect of dust accumulation onto the surface of the unclean module for May and June. Results show that dust accumulation has a great effect on decreasing the daily energy yield of the unclean module. But this effect is a long-term effect. For the cloud cover, the effect is immediate. It was estimated that exposing the module into the environment in 23 days in June 2015 has reduced the daily energy yield by $15.29 \%$. This limitation makes solar PV an unreliable source of power for remote devices and thus strongly suggests the challenges of cleaning the module's surface regularly.

Dedicated to the memory of Professor Abdoulaye Alassane, the first Director of WASCAL Master Research Program on Climate Change and Energy of University Abdou Moumouni

\section{Introduction}

Climate change is becoming a worldwide concern. According to the fifth assessment report of Intergovernmental Panel on Climate Change (IPCC AR5) it is extremely likely that human activities are responsible for climate change [1]. More than $80 \%$ of the global energy production comes from fossil fuels. In 2012 the world electricity produced by coal, oil, and natural gas is estimated to be $9,168,1,128$, and 5,100 TWh, respectively [2]. The world is running out of these energy sources. Also these fossils when burnt produce greenhouse gases like carbon dioxide. Hence the concentration of greenhouse gases is increased and consequently the greenhouse effect is enhanced. So, in order to mitigate this greenhouse effect without compromising our energy generation, there is a need to seek for other alternative energy sources.

The energy sources have been split into three categories: fossils fuels, renewable resources, and the nuclear resources.
Renewable energy resources comprise solar energy, wind energy, bioenergy, tidal energy, and geothermal energy.

According to World Energy Council scenarios, the socioeconomic potential of renewable energy could supply $20 \%$ of global energy by 2030 and $50 \%$ by 2050 . This would offset $420 \mathrm{MtCequi} /$ year by 2020.

Among these renewable energy resources, solar photovoltaic energy represents one of the most promising energy resources [3].

Though the efficiency of solar modules is low, the environmental conditions may further reduce their output and efficiency and bring the system to an altering situation.

Many studies throughout the world have been done to study the effect of dust on the performance of the photovoltaic system [4-6]. But these studies are site specific. Indeed Hassan et al. (2013) have revealed a higher degradation on PV performance (33.5\% to $65.8 \%$ for an exposure of 1-6 months). 
Also [6] showed a decrease in the output power by $17.4 \%$ per month.

In addition, the cloud shadow effect on distributed photovoltaic generation has been also investigated in Massachusetts. Observations and analyses of the solar irradiance and photovoltaic performance showed that there are insufficient step changes in load levels to cause voltage flicker problems [7]. Also the cloud cover impact on photovoltaic production in South Africa was investigated [8]. But, over the study area, no such work has been done for at least a timescale of one month to quantify the impacts of dust and even cloud cover on the PV module efficiency.

So this work is an attempt to study the impacts of dust accumulation (for the months of May and June) and cloud cover on a monocrystalline solar module from May to August 2015 in Niamey. Indeed, Niamey has a dusty climate.

Hence, assessing the impacts of these parameters is of great importance for reliable planning of solar photovoltaic energy use.

\section{Theory behind Solar Photovoltaic}

The sun is the most significant source of renewable energy. The photovoltaic cell is a semiconductor device that converts directly the sunlight into electric power. In general, any element that converts sunlight into electricity is called PV device.

Solar energy can be converted into electricity through two mature technologies, the solar PV technology and the CSP technology.

Concentrating solar power (CSP) systems use mirrors or lenses to concentrate a large area of sunlight, or solar thermal energy, onto a small area. Electrical power is produced when the concentrated light is converted into heat, which drives a heat engine (usually a steam turbine) connected to an electrical power generator.

The direct conversion of solar energy into electrical energy is performed by means of photovoltaic (PV) generators.

Generally, the term photovoltaic effect refers to the generation of a potential difference at the junction of two different materials in response to visible or other electromagnetic radiation. Thus, the broad study area of solar energy conversion into electrical energy is denoted as photovoltaic.

2.1. Photovoltaic Cell Operation. A PV cell is a semiconductor $\mathrm{p}-\mathrm{n}$ junction photodiode that can generate electrical power when exposed to light [9]. The principal operation of a PV cell is based on the phenomenon termed as the photovoltaic effect.

The photovoltaic is a combination of the Greek word phos, photos (light, of the light), and the name of the Italian physicist Alessandro Volta (1745-1825). He discovered the first functional electrochemical battery and the unit of electricity. Volt is named after him. Hence, the photovoltaic effect means the generation of a potential difference at the junction of two different materials in response to visible light or other electromagnetic radiation. follows:

The basic processes behind the photovoltaic effect are as

(1) Generation of the charge carriers due to the absorption of photons in the materials that form a junction

(2) Subsequent separation of the photogenerated charge carriers in the junction

(3) Collection of the photogenerated charge carriers at the terminals of the junction.

2.2. Clearness Index. The linkage between the hourly and daily extraterrestrial irradiance (AM0) and the integrated energy density gathered from a horizontal mounted pyranometer is termed as clearness indices. These parameters enable us to characterize the different months in terms of cloud cover and dust. The daily clearness index is the ratio between the measured radiations against energy density for extraterrestrial solar radiation in one day. The daily clearness index is given by the following equation:

$$
K_{G}=\frac{H}{H_{0}},
$$

where $H$ is the global horizontal solar radiation and $H_{0}$ is the extraterrestrial global radiation and is given by the equation

$$
\begin{aligned}
H_{0}= & \frac{1440}{\pi} * I_{0}\left[1+0.034 \cos \left(\frac{2 \pi n}{365}\right)\right] \\
& *\left[\omega_{0} \sin \Phi \cdot \sin \delta+\cos \Phi \cos \delta \sin \omega_{0}\right] .
\end{aligned}
$$

For $K_{G} \rightarrow 1$, atmosphere is clear and, for $K_{G} \rightarrow 0$, the atmosphere is cloudy.

$I_{0}$ is the solar constant and is equal to $0.0082 \mathrm{MJ} / \mathrm{m}^{2} / \mathrm{min}$.

\section{Materials and Methods}

3.1. Materials Used in This Study. For this study, two solar PV modules of peak power equal to $100 \mathrm{Wp}$ for each module have been used. Each module is containing twenty-one monocrystalline solar cells of dimension $16 \times 16 \mathrm{~cm}^{2}$. Two batteries of $76 \mathrm{Ah}$ are used, one battery for each module as a load in this study. The other materials used are: charge regulator to monitor the state of the battery's charge and solar inverter. Two digital multimeters are used for the measurement of the current, voltage, and the temperature. We also used the pyranometer with a datalogger installed in CNES to complete our dataset. This pyranometer provides horizontal global radiation, inclined $\left(15^{\circ}\right)$ global radiation, and diffused radiation each five (5) minutes. The characteristics of the module are shown in Table 1.

3.2. Experimental Set-Up. The two modules are mounted on a metallic support with a tilt angle of $15^{\circ}$ facing south on the rooftop of WASCAL's building. To study the effect of dust accumulation on the surface of the panel, one module is being cleaned every day and the other is not. The modules are connected to charge controllers via cables. From the charge controllers, the two batteries are connected. Figure 1 shows the experimental set-up. Then output current and voltage for each module were recorded each thirty minutes. 
TABLE 1: Module characteristics.

\begin{tabular}{lcccccc}
\hline Peak power $(\mathrm{Wp})$ & $V_{\mathrm{OC}}(\mathrm{V})$ & $I_{\mathrm{SC}}(\mathrm{A})$ & $V_{\mathrm{MP}}(\mathrm{V})$ & $I_{\mathrm{MP}}(\mathrm{A})$ & $\eta(\%)$ & Area $\left(\mathrm{m}^{2}\right)$ \\
\hline 100 & 24 & 6.4 & 17.6 & 5.71 & 17.38 & 0.575 \\
\hline
\end{tabular}
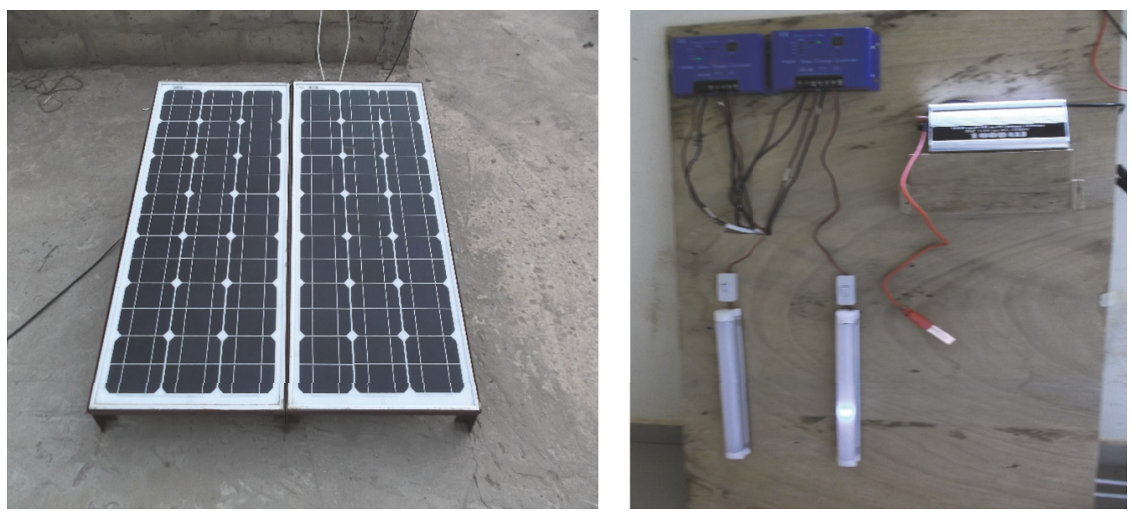

FIGURE 1: Experimental set-up [10].

3.3. Measurements and Data Processing. Output current and voltage for the clean and unclean modules are measured each thirty minutes from May to August. The output power and the daily energy yield of the module are obtained using the following equation:

$$
\begin{aligned}
P_{\mathrm{PV}} & =V * I \\
E_{d} & =\sum_{i=7: 00}^{i=18: 30} P_{i} * 0.5
\end{aligned}
$$

with $P_{\mathrm{PV}}$ being the output power, $V$ the output voltage, $I$ the output current, and $E_{d}$ the daily energy output.

The average daily energy, the monthly energy, and the average daily ambient temperature are obtained using the following equations:

$$
\begin{aligned}
& \bar{E}_{d}=\frac{\sum_{i=1}^{i=31} E_{d i}}{n}, \\
& E_{m}=\sum_{i=1}^{i=31} E_{d i} .
\end{aligned}
$$

The efficiency of the module is calculated using the following relation:

$$
\eta=\frac{P_{\mathrm{PV}}}{P_{\mathrm{rad}}}
$$

with $P_{\text {rad }}$ being the radiation received by the module given by the following equation:

$$
P_{\mathrm{rad}}=G * A .
$$

$G$ is the global inclined radiation and $A$ is the area of the module.

\section{Results and Analyses}

4.1. Daily Variation of Clearness Index. Figure 2 shows the daily variation of clearness index from January to August 2015.

From this figure it is observed that days with minimum values $(\leq 0.2)$ of clearness index are observed in June, July, and August 2015. These minimum values can be attributed either to cloudy phenomenon or to dust haze depending on the season. For example, from January to May and even in June the minimum values of clearness index are probably attributed to dust haze. In contrast, in July and August they are probably attributed to rainy cloud. However, in this work, only the months from May to August will be considered.

Indeed, the clearness index has an impact on the incoming solar radiation, which affects the daily energy output of the PV module. Figure 3 illustrates the relationship between the clearness index and the daily energy output for the months of May and June. It is observed on this figure that maximum clearness index corresponds to maximum daily energy output over the study area.

4.2. Impacts of Cloud Cover on the Photovoltaic Power Output. Figure 4 shows the different profiles of PV daily power recorded on cloudy days for the months of May, June, July, and August.

Figure 4 shows different profiles of the PV module recorded in cloudy days for the months of May, June, July, and August. The clouds impacts are more pronounced in August and July. Indeed, on 7th of August 2015, the maximum power was completely below $25 \%$ of the rated power $(25 \mathrm{~W})$. This is due to the very high cloudy conditions often observed in August that is the month of peak rainfall over Sahel.

4.3. Impacts of Dust Accumulation on Photovoltaic Performance. The heavy layer of dust accumulation on PV module 

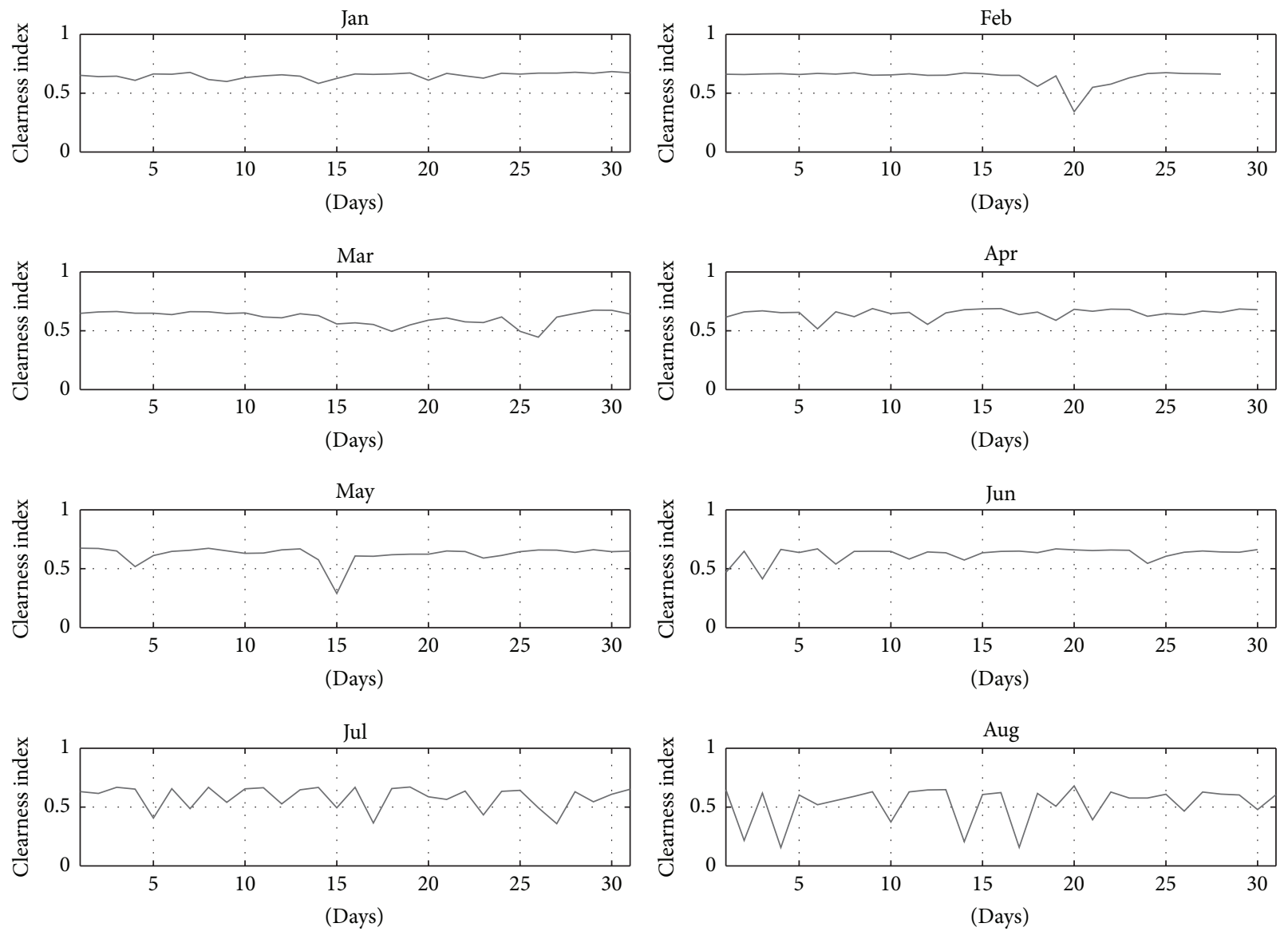

FIgURE 2: Daily variation of clearness index from January to August 2015 [10].
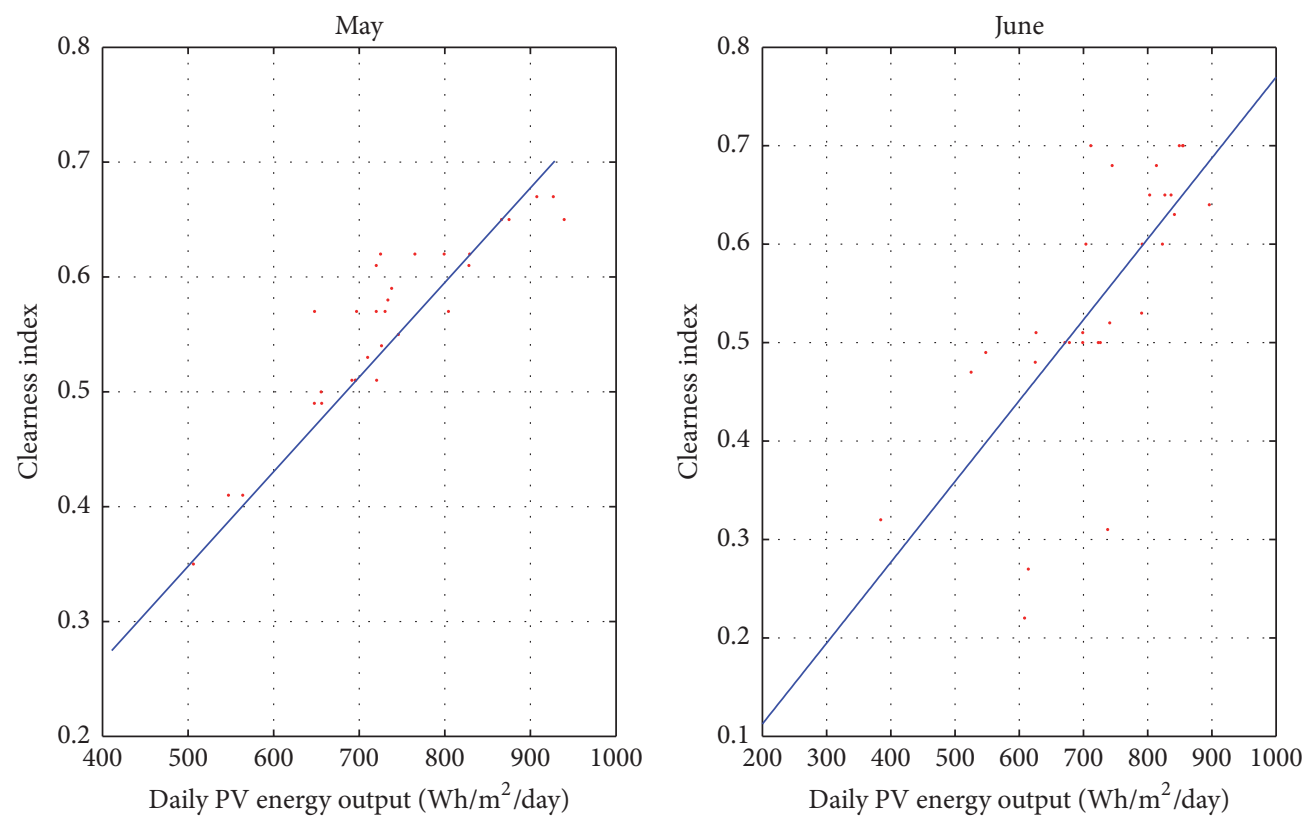

Figure 3: Relationship between the daily energy output and the clearness index. 

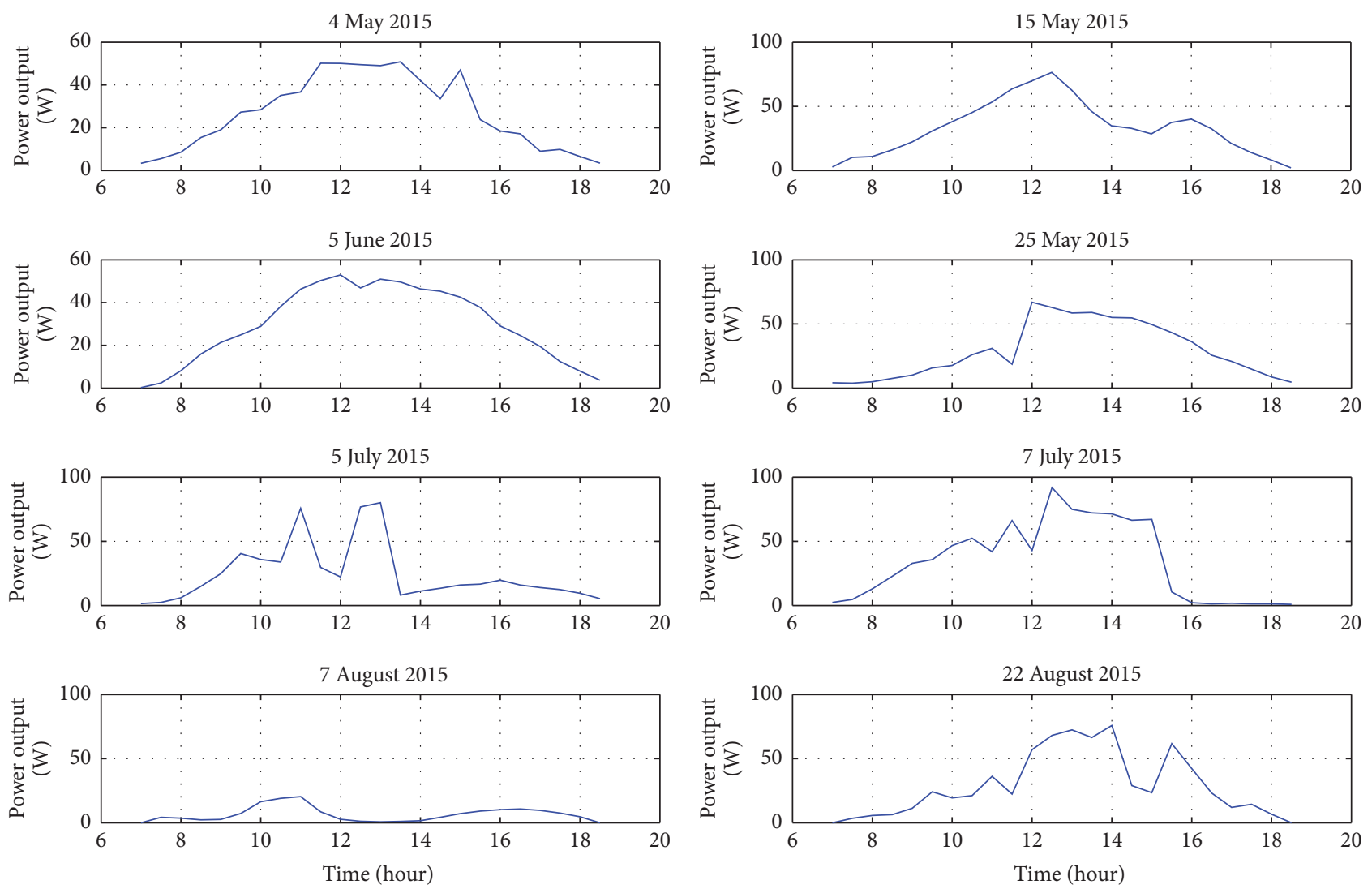

FIGURE 4: Profiles corresponding to cloudy days [10].

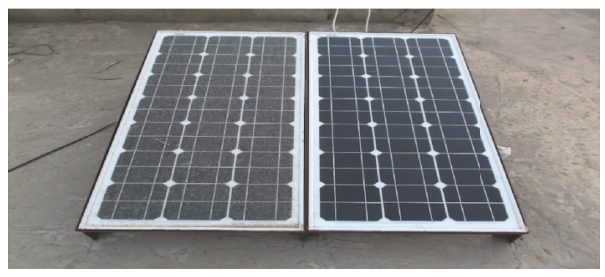

(a)

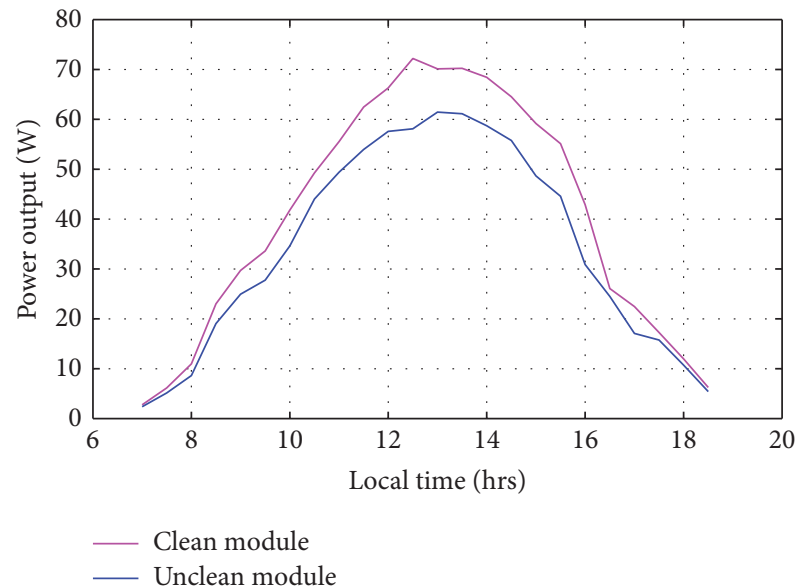

(b)

Figure 5: (a) Pictures of clean and unclean PV modules at 23rd June 2015. (b) Profiles of power output (W) of clean and unclean module at 23rd June 2015 .

causes reduction in output power and hence on the daily output energy yield that can be however recovered by cleaning the module.

Figure 5 is to illustrate the impact of dust on the daily output profile of the PV module. It is clearly observed that, after only 23 days of exposure of the module without cleaning it, the power drops up to $10 \%$ of the rate in June 2015 (Figure 4). Consequently, the daily energy of the PV will also drop.
The daily energy variation for both the clean and the unclean modules for the months of May and June 2015 is shown in Figures 6 and 7, respectively.

The difference of energy $(\Delta E)$ between the two PV modules increases, when the number of days increases. This observation is illustrated in Figure 8. This $\Delta E$ is more noticeable with maximum energy recorded. The minimum daily energy value for both the two modules is recorded on 


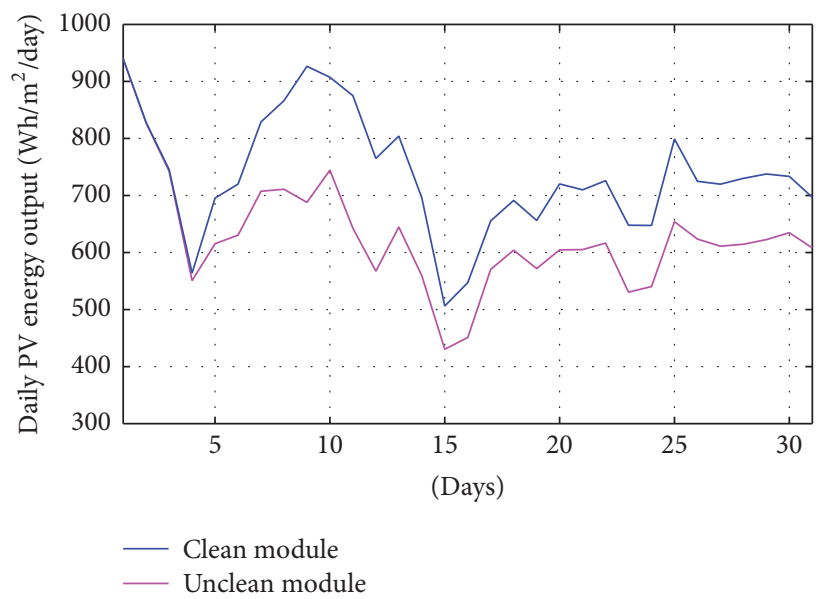

FIGURE 6: Daily energy yield for the clean and unclean module in May 2015.

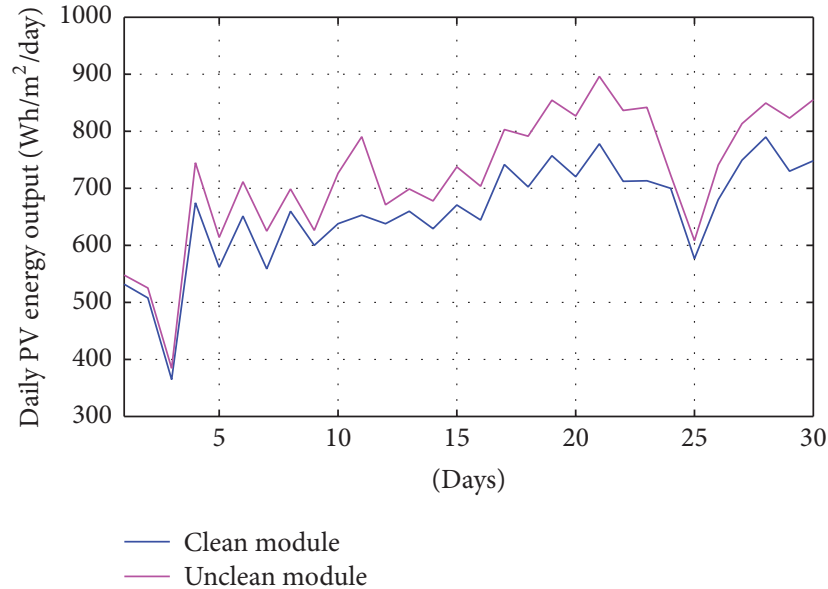

Figure 7: Daily energy for the clean and unclean module in June 2015.

15th of May 2015 (see Figure 6). This is due to heavy dust recorded that day which has drastically reduced the clearness index (Figure 2).

Like in the previous graph, $\Delta E$ increases with the increase in number of days. However, on 24th of June, this value drops because of the rainfall that washes the unclean PV module that day.

Figure 8 illustrates the evolution of the difference of energy between the clean and unclean module as a function of time.

4.4. Discussions of the Results. From Figure 2, it is observed that the minimum clearness index value is observed on 15 th of May 2015. However, Figure 4 shows also that, on the same date, the daily energy produced by the solar module is minimum. So from these two figures it can be concluded that the daily energy output is a function of clearness index. Furthermore, the days with minimum values of daily energy observed in July and August 2015 correspond exactly to the days with lower clearness index. Indeed, the minimum clearness index is related to either dust haze or cloud cover that reduces drastically the direct component of solar irradiance reaching the surface of the module.

The lower values of clearness index and daily energy of the module in July and August 2015 are mainly due to heavy rainy cloud whereas in May and June 2015 they are partly due to dust haze and cloud cover.

From the results above, it is shown that both the cloud cover and the dust accumulation have a great effect on the performance of photovoltaic module. The cloud cover impact is only observed mainly in July and August 2015.

Cloud weakens drastically the incoming direct component of solar radiation reaching the surface of the module resulting in minimum output power. So the daily energy produced by the module is lower compared to cloudless days. Suri et al. [8] also found similar results, showing the decrease of PV energy due to the impacts of cloud cover.

The dust accumulation also has a great impact on the power output of the module. Indeed, up to $10 \%$ reduction in power has been observed for only 23 days. Similar works have been also carried out to assess dust accumulation impact on the power output of the solar PV modules. In Pakistan, [11] found, for a period of three months, $20 \%$ and $16 \%$ decrease of output power for the monocrystalline and polycrystalline modules, respectively. The same work has been done in Senegal for one year without cleaning the PV modules and that resulted in a loss of $18 \%$ and $78 \%$ for the polycrystalline and monocrystalline, respectively [12].

The daily energy of the clean module is higher than the unclean one. Exposure of the module in June within 23 days without cleaning it has reduced the daily energy output by $15.29 \%$. Similar effects of dust accumulation on the PV energy have been also found in other parts of the world. $32 \%$ reduction was found in Saudi Arabia [13]. Another study carried out by Hassan et al. (2015) showed a reduction ranging from 33.5 to $65.8 \%$ for a period of one to six months, respectively. In the tropical climate of Thailand, $11 \%$ of reduction has been observed for the period of one month [14]. Then, in United States, an average reduction of 1 to $4.7 \%$ in a two 

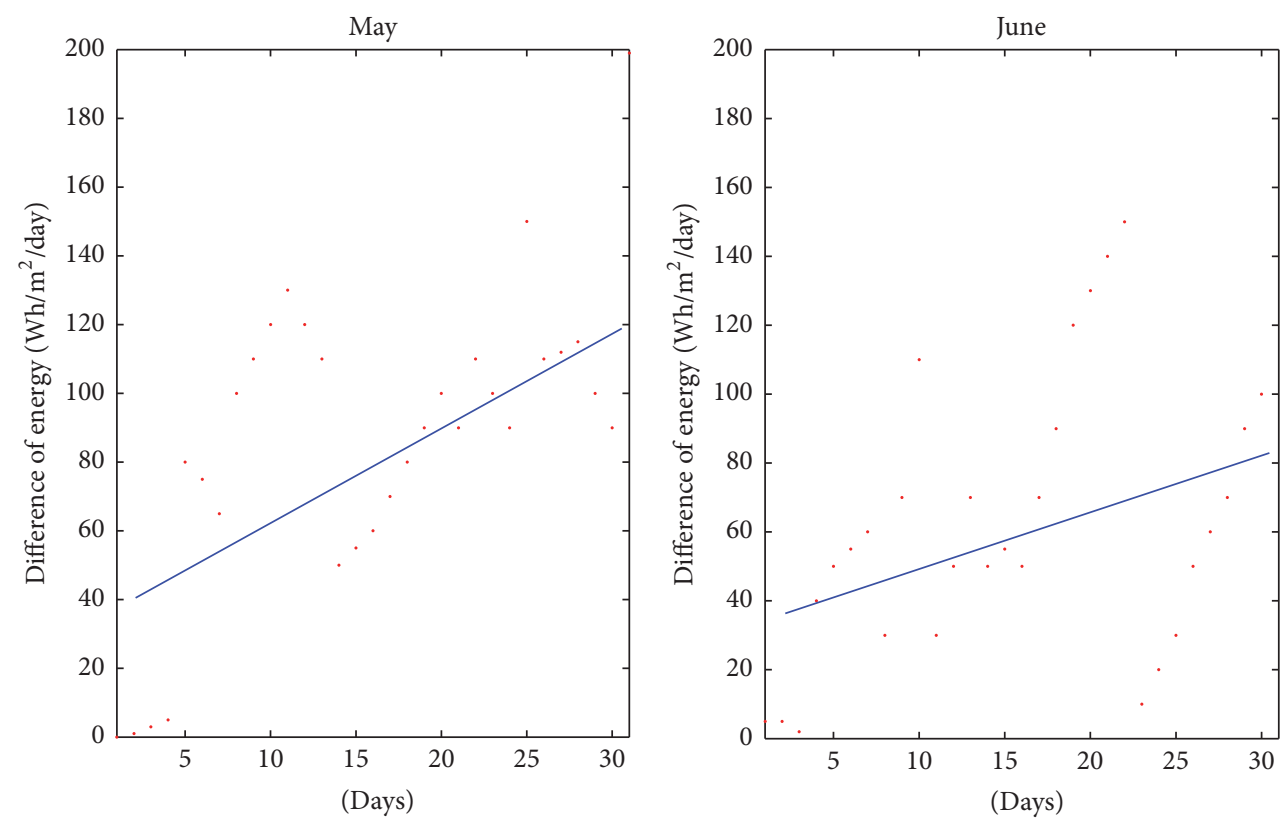

Figure 8: Difference of energy as a function of the number of days.

months' period has been reported in [15]. All these results show that the impacts of dust on the performance of solar PV module vary from one location to another. Hence, this requires different studies at different sites.

\section{Conclusion and Future Work}

In this paper, the effects of cloud cover and dust accumulation on the performance of the photovoltaic solar module have been investigated from June to August 2015 in Niamey. Results show that both the cloud cover and the dust accumulation onto the surface of the solar module have a great impact on photovoltaic solar performance. The effect of cloud cover is immediate with a drop in global solar irradiance and hence in power output for a short time, while the effect of dust accumulation has a long-term effect.

In July, and August 2015 the heavy cloud blocks the direct component of the solar irradiance resulting to minimum value of daily energy.

For the dust accumulation effect, it reflects the incoming solar radiation reaching the solar module resulting hence to decrease the energy output of the module. So it is very worthy to clean the module more frequently in order to minimize the loss due to dust accumulation especially in a dusty environment.

In perspective, this study should be conducted further to perform the effect of dust with different types of cell technologies in order to see which of these technologies is more suitable for the area of study. We highly recommend also perform the measurement for all the months in order to know in which of the months the module is more affected by dust accumulation and cloud cover. Also perform the measurements at different geographical points might improve the results of this work.

\section{Nomenclature}

\section{Abbreviations}

IPCC AR5: Intergovernmental Panel on Climate Change Assessment Report 5

PV: $\quad$ Photovoltaic

$P_{\mathrm{PV}}: \quad$ Photovoltaic power output

CSP: $\quad$ Concentrating Solar Power

$\mathrm{H}_{0}$ : $\quad$ Extraterrestrial solar radiation

CNES: National Center of Solar Energy

$I_{0}$ : $\quad$ Solar constant

kWp: $\quad$ Kilowatt peak

$K_{G}: \quad$ Daily clearness index

$H$ : $\quad$ Horizontal global solar radiation

$P_{\text {rad }}: \quad$ Radiation received by the panel

$E_{d}: \quad$ Daily energy yield

$E_{m}: \quad$ Monthly energy yield

$G$ : Global solar radiation

A: $\quad$ Area of the panel.

\section{Greeks Symbols and Units}
$\omega_{0}$ : Sunset hour angle
$\phi: \quad$ Latitude
$\delta: \quad$ Declination angle
$\eta$ : $\quad$ Conversion efficiency

TWh: Terawatt-hour

A: Ampere

V: Volt

$\mathrm{M}^{2}$ : $\quad$ Square meter

W: Watt

${ }^{\circ} \mathrm{C}$ : Degree Celsius

MJ: Mega joule

min: Minute. 


\section{Conflicts of Interest}

The authors declare that there are no conflicts of interest regarding the publication of this paper.

\section{Acknowledgments}

First of all, the authors would like to acknowledge with thanks the BMBF, the Germany Federal Ministry of Education and Research, and the West African Science Service Center on Climate Change and Adapted Land Uses (WASCAL) for providing them with the scholarship and financial support during their Master Research Program. This work is a contribution of the West African Science Service Center on Climate Change and Adapted Land Uses- (WASCAL-) MRP Climate Change and Energy of University Abdou Moumouni, Niamey (Niger).

\section{References}

[1] "Intergovenmental panel on climte change," IPCC Fifth Assessment Report, 2013.

[2] International Energy Agency, "Key world energy statistics," International Energy Agency, 82 pages, 2014.

[3] R. Hill, "Prospects for Photovoltaics," World Energy, 1999, original data updated by Hynes K. and Hill R. in 1999.

[4] M. S. El-Shobokshy and F. M. Hussein, "Effect of dust with different physical properties on the performance of photovoltaic cells," Solar Energy, vol. 51, no. 6, pp. 505-511, 1993.

[5] F. Touati, A. Massoud, J. A. Hamad, and S. A. Saeed, "Effects of environmental and climatic conditions on PV efficiency in Qatar," in Proceedings of the International Conference on Renewable Energies and Power Quality, pp. 20-22, 2013.

[6] H. K. Elminir, A. E. Ghitas, R. H. Hamid, F. El-Hussainy, M. M. Beheary, and K. M. Abdel-Moneim, "Effect of dust on the transparent cover of solar collectors," Energy Conversion and Management, vol. 47, no. 18-19, pp. 3192-3203, 2006.

[7] E. C. Kern Jr., E. M. Gulachenski, and G. A. Kern, "Cloud effects on distributed photovoltaic generation: slow transients at the Gardner, Massachusetts photovoltaic experiment," IEEE Transactions on Energy Conversion, vol. 4, no. 2, pp. 184-190, 1989.

[8] M. Suri, T. Cebecauer, A. Skoczek, R. Marais, C. Mushwana, and J. Reinecke, "Cloud cover impact on photovoltaic power production in South Africa," in Proceedings of the 2nd South African Solar Energy Conference, Port Elizabeth, South Africa, 2014.

[9] S. Said, A. Massoud, M. Benammar, and S. Ahmed, "A matlab/similink photovoltaic array model employing Simpower system toolbox," Journal of Energy and Power Engeneering, pp. 1965-1972, 2012.

[10] Bonkaney, Climate Change and Energy, 2015, http://www .wascal-ne.org/bonkaney.html.

[11] H. M. Ali, M. A. Zafar, M. A. Bashir, M. A. Nasir, M. Ali, and M. A. Siddiqui, "Effect of dust deposition on the performance of photovoltaic modules in Taxila, Pakistan," Thermal Science, pp. 46-46, 2015.

[12] A. Ndiaye, C. F. Kebe, P. A. Ndiaye, A. Charki, A. Kobi, and V. Sambou, "Impacts of dust on the photovoltaic (PV) module characteristics after an exposition year in Sahelian environment: the case of Senegal," International Journal of Physical Sciences, pp. 1166-1173, 2013.
[13] M. Mani and R. Pillai, "Impacts of dust on solar photovoltaic (PV) performance: research status, challenges and recommendations," Renewables and saistainable energy reviews, pp. 28812887, 2010.

[14] G. A. Mastekbayeva and S. Kumar, "Effect of dust on the transmittance of low density polyethylene glazing in a tropical climate," Solar Energy, vol. 68, no. 2, pp. 135-141, 2000.

[15] H. Hottel and B. Woertz, "Performance of flat-plate solar heat collectors," ASME Journal, vol. 64, pp. 91-104, 1942. 


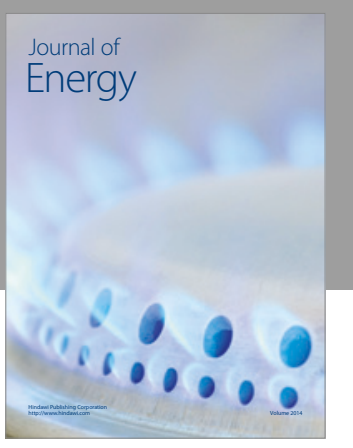

Journal of

Industrial Engineering
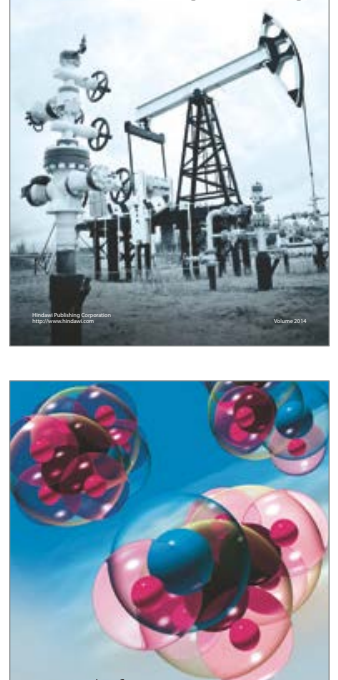

Fuels
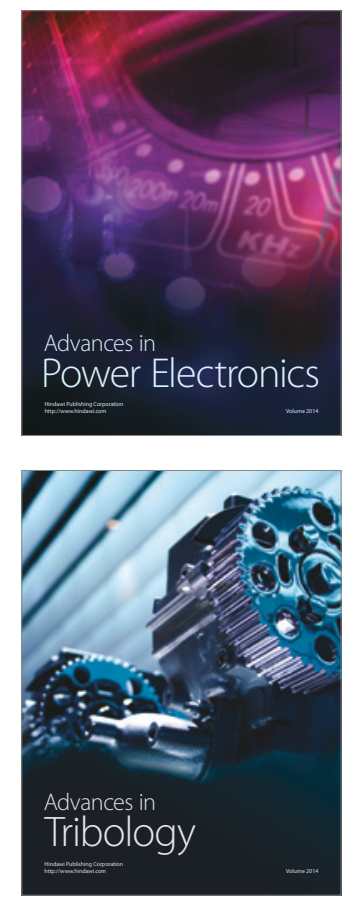
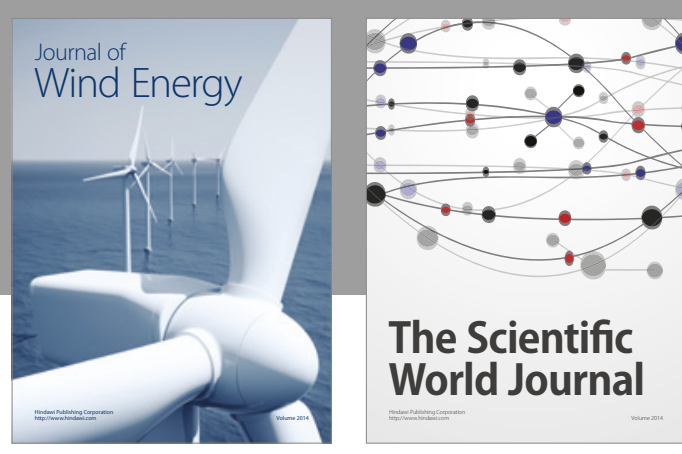

The Scientific World Journal
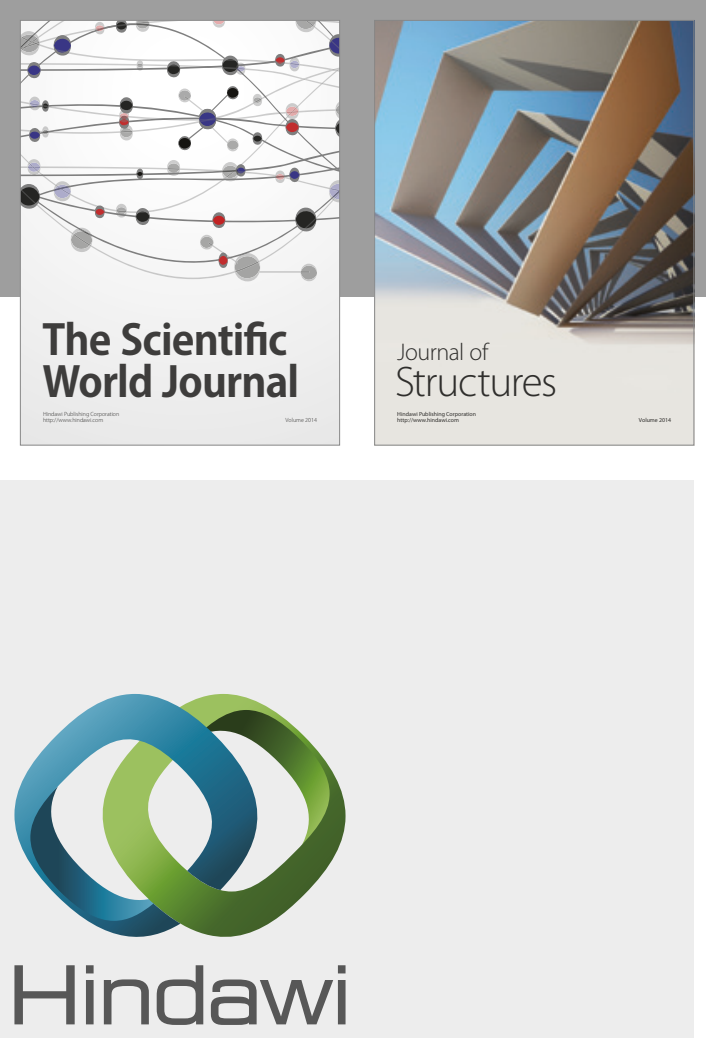

Submit your manuscripts at

https://www.hindawi.com
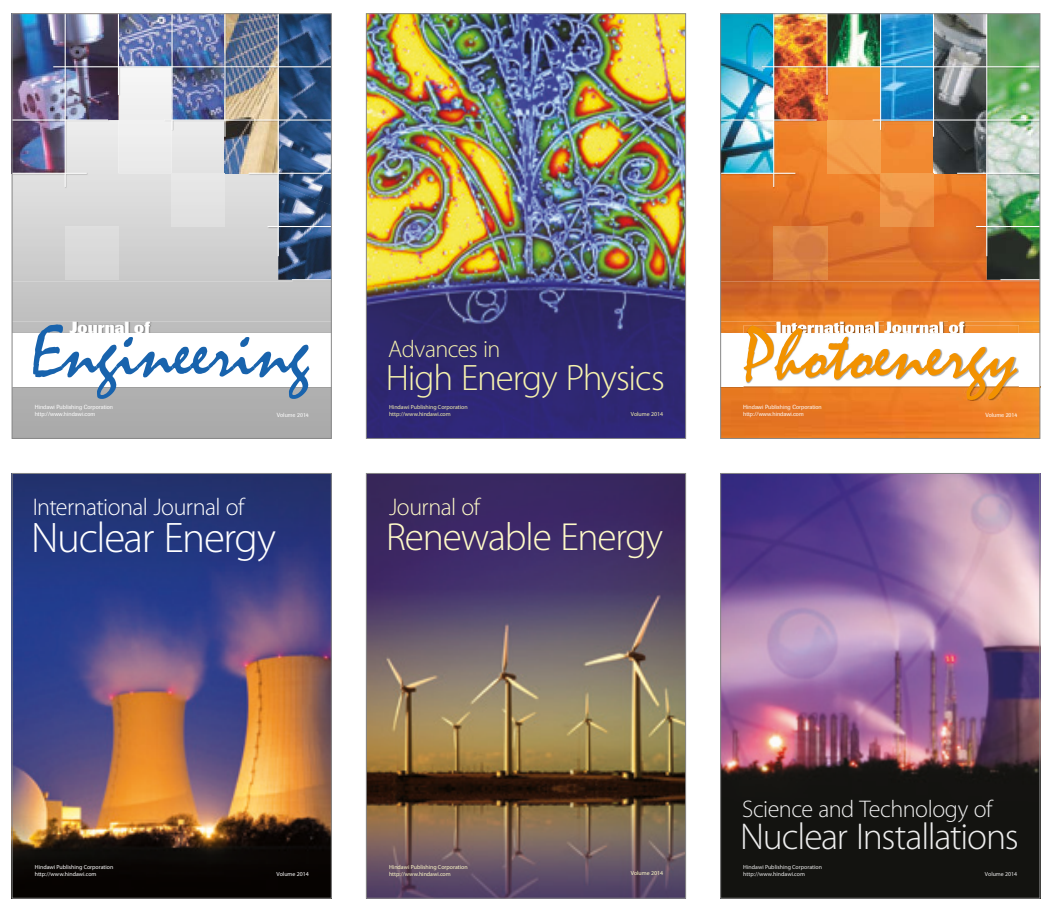

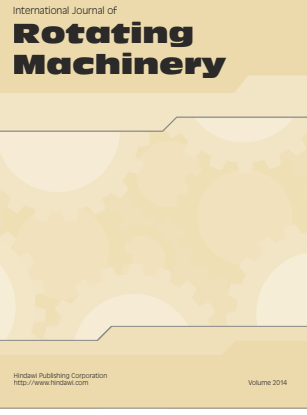

Journal of

Petroleum Engineering

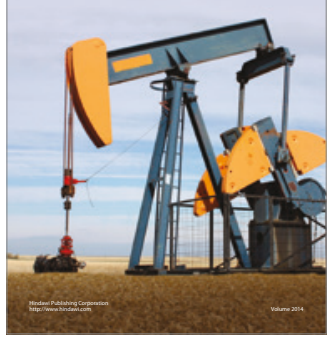

Journal of
Solar Energy
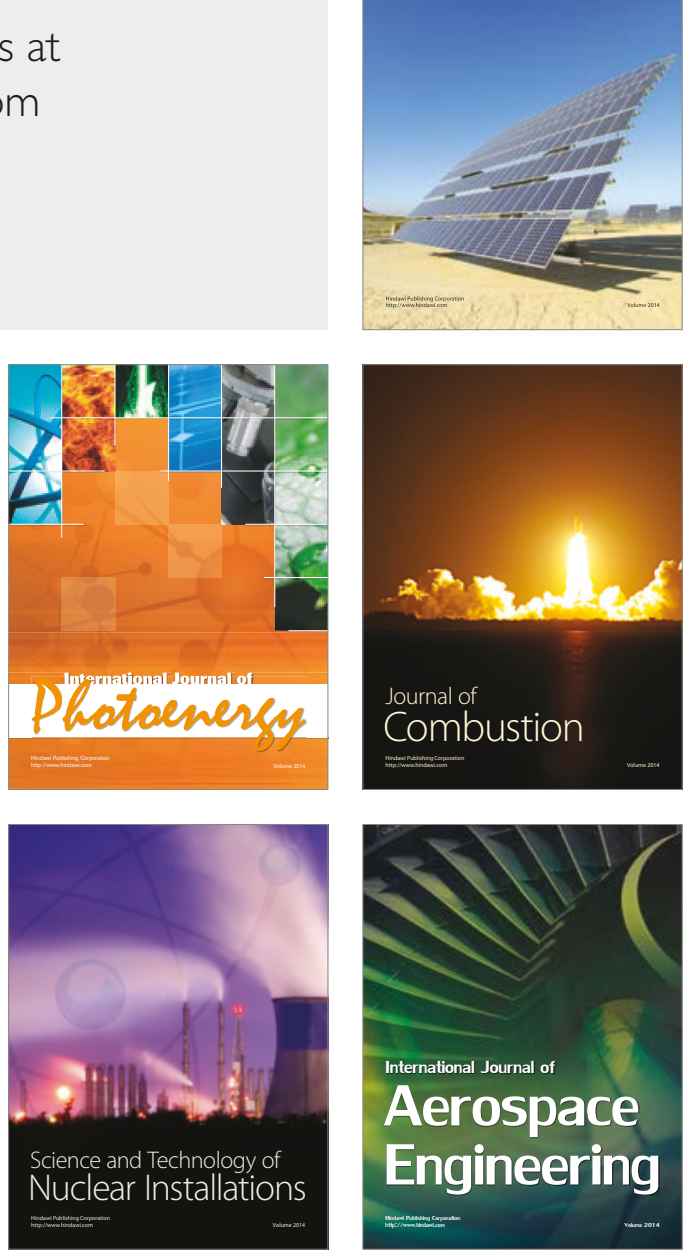